\title{
Yoga for All and Social Transformation Through Body and Mind: Team Yoga and Case of The Tsukuba Health Project
}

\author{
Randeep Rakwall,2*, Genboku Takahashi ${ }^{3}$ and Seiji Shioda ${ }^{2}$ \\ ${ }^{1}$ Faculty of Health and Sport Sciences, University of Tsukuba, Japan \\ ${ }^{2}$ Global Research Center for Innovative Life Science, Hoshi University, Japan \\ ${ }^{3} Z e n-Y o g a$ Institute, Japan
}

Submission: August 27, 2018; Published: September 18, 2018

*Corresponding author: Randeep Rakwal, Faculty of Health and Sport Sciences, University of Tsukuba, 1-1-1, Tennodai, Tsukuba, Ibaraki, 3058574, Japan, Email: plantproteomics@gmail.com

\begin{abstract}
Japanese society today faces numerous challenges as any other country; however, with the increasing and aging population the public's anxiety towards its current state and future development is great. Focusing on citizen's health, society faces numerous health problems such as increased psychosomatic disorder, depression and neurosis due to stress, increase in lifestyle diseases due to satiation and lack of physical activity and sport, and severe dementia and being bedridden in aged society. Under these circumstances, preventive measures such as specific health examinations/specific health guidance for metabolic syndrome and "Health Japan 21" project, etc., are being carried out in the country. However, and despite the huge efforts of the prefectural municipal administrations, it is hard to say that they have been successful. For example, and as for the case being discussed in this article for Tsukuba-city, considered as a science city, these problems are serious. In response to these problems, a working group of teachers, professionals, scientists and students has been established. It is called "team yoga" and proposes "yoga for all" as a base for establishment of the "Tsukuba Health Project" in recognition that support for individuals and society from the standpoint of comprehensive alternative medicine is necessary and urgent. The ultimate goal is to help people to form their self-transformation direction leading to social transformation. The reason for aiming for social contribution is that the field where yoga can be used is widely diverse including physical education, health and sanitation, education, mental health, sports, and entertainment.
\end{abstract}

Keywords: Yoga practice and wisdom; Concentration; Health and recovery; Sport; Athlete; Social transformation

\section{Introduction}

Today, the public concern about physical decline and health problems due to aging is high, in the world and that includes Japan too [1]. In particular, various preventive measures and interventions are discussed and taken against various life-style disorders/diseases including "metabolic syndrome", cancer and dementia through various arms of the society, public, including government, and private sector as the industry, and academia in Japan [2,3]. Let us look a bit more carefully about this below, in Japanese context and the need for 'Yoga for All' in context of Tsukuba city, Ibaraki, Japan, and the proposal for a 'Tsukuba Health Project'.

\section{The aging population, bedridden and financial impli- cations in Japan context}

Briefly, to note, in Japan, the population of elderly people aged 65 has reached 33.84 million (Heisei 27, Ministry of Internal Affairs and Communications, Government of Japan, 2015). This number, in proportion to the total population, is
$26.7 \%$, and Japan is in the middle of a super-aged society; and, it is well known that the main causes of death are cancer and cardiovascular and cerebrovascular diseases. However, what will give serious damage to our life will be from a state requiring nursing care to bedridden. Nowadays, the term "healthy life" is used, but its seriousness is not well understood.

The most common cause of bedridden is stroke. Stroke begins with metabolic syndrome. Metabolic syndrome is a combination of an increase in visceral fat and hyperglycemia, hypertension, hyperlipidemia, etc. When this state is reached, the aging of the blood vessel rapidly progresses and the risk of stroke to being bedridden eventually increase. In addition, the probability of developing dementia increases with age, but it often becomes bedridden from dementia. Because dementia causes memory loss and personality transformation, which no one wants, but $30 \%$ is dementia and is due to cerebrovascular disease. It is not uncommon for the bedridden period from stroke to extend over a longer period than other causes, and over 3 years. Once a 
person becomes bedridden, it is not only oneself who suffers. If the bedridden period becomes long, the family will suffer both mentally and physically due to nursing care, and eventually one will have to quit his/her job and even this will evolve to suicide and crime from poverty and despair. Furthermore, the health problem is also important in that it greatly strains the national finance.

Looking at national medical expenses, it was over 40 trillion yen in Heisei 20 (FY 2008), the nursing care expenditure in this year exceeded 9 trillion yen, and in 1979 it was 9,919.9 billion yen (a 2.4\% increase) and approaching 10 trillion yen. Also, each local government presents a huge cost pressing the fiscal budget. For example, in Tsukuba city with population 220,166 people (as of April 1, 2015) general figures of Heisei 20 fiscal year (2008) and special accounting settlements in numerical values are as follows. The annual expenditure amount of the city is about $31,062,764,000$ yen among $114,940,320,000$ yen (FY 2004) (National Health Insurance: 18,521,589,000 yen, Medical Care Insurance for Late Older Persons: 1,397,476,000 yen, Long-Term Care Insurance Business: 11,143,699,000 yen) it is devoted to medical care and nursing care. Concern for such a situation was from the end of the 20th century, and the longterm care insurance law came into effect in year 2000 (Heisei 12). Healthy 21 (the National Health Promotion Campaign in the 21st century) that appeared spectacularly this year also. And in the year 2008, metabolic examinations began; interventions by citizens began to take place.

\section{Japan public perception and complementary alterna- tive medicine and university of Tsukuba}

What has become understood to the public by these measures is not only that it can be prevented by improvement of lifestyle such as moderate exercise, improvement of dietary habits (nutrition), rest (fatigue and stress measures), but also medical science; it is also considered to be important as an aid to the treatment. Improvement of lifestyle is necessary regardless of the target age from infancy to 100 years old. For these reasons, efforts to improve health based on the theme of improvement of lifestyle habits from the standpoint of each - industry, government, academia and citizens have been carried out. By the way, moderate exercise, improvement of dietary habits (nutrition), recreation method (fatigue and stress control), etc., is closer to the approach of complementary alternative medicine (CAM) rather than modern medicine and nutrition. In fact, in recent years the need for CAM approaches has come to be recognized.

Research and intervention experiments have been conducted at the University of Tsukuba in the fields of medicine and physical education. For example, in physical education, a research project (BAMIS project; http://bamis.taiiku.tsukuba. ac.jp/english/index.html) was conducted from the perspective of a single mind and body (brain and brawn-one and the same). Among them included oriental body techniques such as Yoga and Qigong. Since then, Yoga has received good reviews; including being incorporated into the Graduate General Education Courses (GGEC; http://www.tsukuba.ac.jp/en/study-tsukuba/ study-graduate/kyoutsuukamoku) program of the University of Tsukuba (UT) aiming to cultivate human power/potential. Physical techniques like yoga have a status as CAM. CAM has been recognized in the United States of America for its necessity, and it has been affected in that way, and it has been used more frequently in medical and nursing situations even in Japan. CAM gradually gains attention as an important aspect in supplementing the part that modern medicine is losing. However, it is only partially introducing the technology of CAM, and it seems that it has not yet been used correctly in its whole way.

Tsukuba city (http://www.tsukubainfo.jp/) being a young city created out of a need for bring science and technology at one location is the perfect place to begin to study, practice and understand the YOGA concept. Therein, lies the role of University of Tsukuba and the YOGA course of the GGEC program (http:// www.tsukuba.ac.jp/education/g-courses/detail.php?subject_ id=1116) followed by the social innovation projects and activities in Team Yoga (http://teamyoga5.wpblog.jp/) over the past 5 years from inception of the program to its widespread popularity today among not only the graduate students but also people from all walks of life from and around Tsukuba and Tokyo.

\section{Concept and Intention of Team Yoga}

Five years evolution of the Yoga course at University of Tsukuba (GGEC program) underlies the work presented in this short article for the Journal of Yoga and Physiotherapy, which is we believe a perfect platform to present this perspective on Yoga, Health, and Social Transformation.

\section{Policy}

Yoga is recognized as a world culture, today. Yoga has no relation to state, race, religion, sex, age. It is thought that it is comprehensive wisdom and practice to solve the troubles and sufferings arising from human activity. Yoga is used all over the world for physical health, prevention and treatment of depression, neurosis, dementia and measures for stress and pressure, for improvement of the performance in academic and work, etc. In recent years in Japan too, the Yoga population is rapidly increasing. However, little attention has been paid to the true value and possibilities of Yoga. The real value and possibilities of Yoga lies in becoming a person who can live with the aim of self-transformation and social-transformation. Selftransformation here means to look deeply at oneself, regain free self and enrich one's life. In our hearts, there is a heart of fierce desire, anger, envy, jealousy, grudge, and hatred. When this violent heart calms down, a rich heart is born. With this rich mind, we can regain our awareness that "people and people, and people and nature (body is also a part of nature)" is just one. This is Yoga. This is possible for everyone, so we call this "Yoga for All". This makes it possible for everyone to live a life to realize a better society. This is to say- Social Transformation by Yoga. We aim at such self-transformation and social-transformation. 


\section{Background}

Yoga will answer your life problems, will it and how? It seems that everyone, each one of us, has various problems as part and parcel of life. Now the sense of stagnation is spreading in society in Japan. Many young people in their teens and 20s have a sense of frustration because they cannot have a hope in the future. Depression and neurosis are increasing due to it. We are in a severe stress society. The age of the $30 \mathrm{~s}$ and $40 \mathrm{~s}$, is the age when one is performing various duties of marriage, childbirth, child rearing and repayment of loan. Overlap these things and one can find people who have become worn out in body and mind; it is not uncommon. For these reasons, there are an increasing number of people suffering from sudden myocardial infarction and death from overwork. In the era of nuclear families, the number of mothers who are suffering from solitary child rearing is on the rise. Also, gender issues are serious for working women.

From the late 40 s to the 50 s, it will be climacteric age. Before we know it, we are now in the age to worry about 'metabolic syndrome', blood pressure and blood sugar, the neutral fat. It is noticed that "I am not young anymore" by the gap of values between oneself and the younger generation. Middle managers will be in dire straits, and $\mathrm{h} / \mathrm{she}$ is sandwiched between the bosses and subordinates. Comes to 50 s to the 60 s generations, one will notice a limit to - "my potential". People might have been dreamed of a happy life in younger times. However, many people say that such dreams have already disappeared. Health, family, economy, status, and so on are on one's mind. The feeling will still be young. But, beyond 70 years of age, one feels weakness both physically and mentally. Then, the voice of the creeping death can be heard even greater. Children have gone out of the house a long time ago. It is also not uncommon that after experiencing the deaths within the family and of friends, people walk the lonely road. Some people suffer strokes from diabetes and high blood pressure, become bedridden, or advance into dementia. The family who does nursing is also tired from spirit and physically; and because the work cannot be continued, it is not rare to see people fall into poverty.

Such a predicament is, and we think, not only in modern Japan. Does similar difficulty not approach us, even if we live anywhere in any time? Yoga was born 4,500 years ago to make people to be free from such predicament. Not only has it been transferred to the present day, it is spreading all over the world. We think that this indicates that Yoga is a powerful force in solving human problems.

\section{History and achievements at University of Tsukuba - GGEC yoga course}

In 2015, Prof. Randeep Rakwal (Faculty of Heath and Sport Sciences and TIAS) got support of Prof. Hideaki Soya and Prof. Yosuke Sakairi at University of Tsukuba Faculty of Health and Sport Sciences and received Genboku Takahashi as a Guest Teacher and opened Yoga class at the GGEC program. Students at Yoga Course will learn about the profound Yoga philosophy and scientific understanding of Yoga. And, that it is also the purpose of this course under the GGEC mission to foster human nature (in graduate students) that enables the socialtransformation activities. This course continues to date. The number of attendance request by students (both Japanese and International) to this course greatly exceeds recruitment every year. The student's attendance rate is very high, and they are in the class with an amazing concentration.

\section{Yoga for all}

One reason why student are interested is that Yoga like this (course of theory linked to practice) is lacking in today's Japanese contemporary society. Thinking like this, Randeep Rakwal and Genboku Takahashi, opened the "Yoga for All" for the general public in University of Tsukuba Satellite Office at "Bivi" (Tsukuba Center) in 2016. Inquiries were received from a wide range of people and organizations in Ibaraki prefecture. The participants increased every time and overflowed, finally.

\section{others}

On June 21, 2016, in accordance with International Yoga Day, a Yoga lecture and practical in the Central Library of the University of Tsukuba was done. On June 28, we did Yoga with the students at "Otsuka Olympics Paralympic Day 2016" at Special Needs Education School for the Mentally Challenged (UT).

\section{Formation of "Team Yoga"}

Gradually with time and students, ex-students and friends, starting from the time of opening the GGEC Yoga Course, gathered together, and we formed "Team Yoga". Our purpose is the spread of Yoga more and more, and to establish a Yoga Center before long; and to develop human resources and create socialtransformation.

\section{Aim of the Tsukuba Health Project}

Techniques such as CAM, e.g., Yoga, Ayurveda, Aromatherapy, Phytotherapy, Acupuncture and Chinese medicine each have their own life sense; technology based on life philosophy that has been cultivated in the history of more than 1000 years. Meanwhile, modern medicine and nutrition have no sense of life, life or philosophical approach as to how to see the health of living beings as human beings. In other words, medicine and health projects based on mechanistic life view are still underway. That said, in reality, many medical doctors, researchers, nurses, public health nurses and other health care workers have to question the current state of modern medicine and change something fundamental; and it is also a fact that we are thinking seriously. And, to note, we are not alone in this thinking (please see also, some selected texts - http://yogachicago.com/2014/01/yogafor-health-and-social-transformation-its-about-yoga-researchpolitics-business-and-culture/) [4-8].

We are aiming to face this question and to make the best use of CAM in medical and health exercise areas. The (Figure 1) below is a conceptual diagram centered on yoga/aromatherapy, nursing/care and food for understanding this. 


\section{Yoga and nurse}

Let us take an example of nursing, among others in (Figure 1 ), to discuss in further detail. It goes without saying that here again, how extremely important the role of nurses (such as nurses, public health nurses, midwives) is in tasks that contribute to treatment and health promotion, facing the lives of patients and local residents alike. Such work is located between Western medicine and CAM. First of all, we would like to show that yoga can contribute to make such nursing work better. Although yoga is extremely useful for physical health care, in recent years full-scale verification has been carried out even in Japan, and utilization at the medical field has been actively carried out. For example, there is research by Ministry of Health, Labor and Welfare. Nonetheless, it is not the doctor who uses yoga to care for patients, but mainly this goes to nursing, nursing care, rehabilitation staffs, etc. Yet more than that, yoga is considered useful for health management of nurses, public health nurses and others. When asked to a public health nurse who received the Yoga course lecture and training under the GGEC program, the question - "What kind of thing does everyone in nursing feel necessary for care of their own personal matters, and what kind of thing would be useful if you are involved in nursing jobs?" The answer was as follows - "I think that the work of a nurse is always a series of nervousness, and furthermore, I think that the condition of irregular working is the biggest point. Yoga can relax the mind and body and to take a good/meaningful rest, I think that it is necessary."

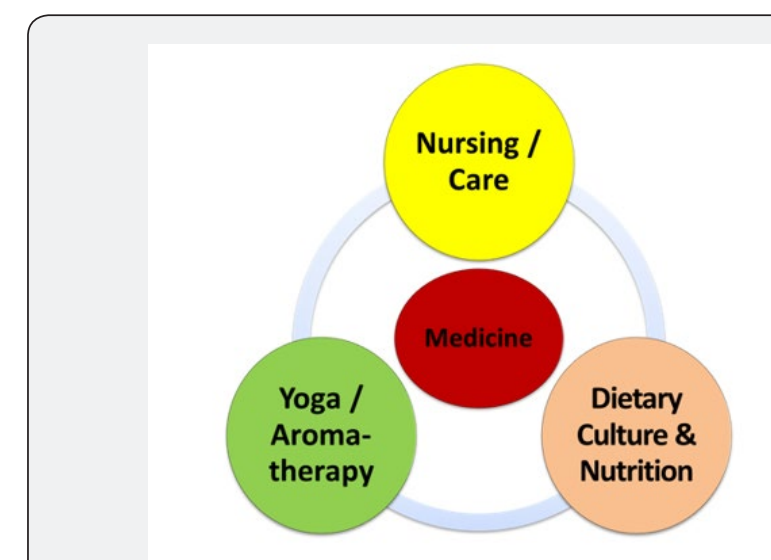

Figure 1: Yoga role in human health-complementary to all.

When a patient is suffering, has trouble, faces to life, nurses and public health nurses themselves question their views on life [9]. A nurse who retired after working at a hospital for decades said, "What the patient appeals is not only due to painfulness from illness and pain, but also family issues, lovers, things of the future, things of a long time ago (the past); and, in the face of death, how to confront the fear, the content that we must deal with within a limited time of business is beyond the framework of counseling." What you need for these tasks will be selfdiscipline and established life philosophy. In this regard, Yoga is useful when one faces a very serious problem.

Similarly, in the case of food for body and mind; and, today's health problems are thought to be solved considerably by having the entire society as a whole with correct dietary thought. What supports the food culture is nothing but agriculture? The person who advocated organic agriculture for the first time in the world was Sir Albert Howard (1873-1947), a British botanist. He left the following words in 1926 as the Oriental wisdom he learned from Indian small-holding farmers. "The health of soil, plant, animal and man is one and indivisible". This thought is the idea of yoga. Yoga traces the path of comfortable living with the foundation facing directly to the life we are living now. Its fundamental mind and body are also a thought that respects the life living together with the natural environment. Based on the Yoga course we worked on from the fear that yoga being disseminated in Japan today is only merely a health law or performance improvement that neglected the basic idea as pointed out in the previous sections, we are now moving towards establish Tsukuba Health Project, not only through comprehensive Yoga education and Asana training/practice, but also through scientific research on how Yoga influences the body at the molecular (omics) level.

\section{References}

1. Kirkwood TBL (2017) Why and how are we living longer? Experimental Physiology 102(9): 1067-1074.

2. Murray CJ, Lopez AD (1997) Alternative projections of mortality and disability by cause 1990-2020: Global burden of disease study. Lancet 349(9064): 1498-1504.

3. Sharma M, Majumdar PK (2009) Occupational lifestyle diseases: An emerging issue. Indian Journal of Occupational and Environmental Medicine 13(3): 109-112.

4. Field T (2016) Yoga research review. Complementary Therapies in Clinical Practice 24: 145-161.

5. Groessl EJ, Chopra D, Mills PJ (2015) An overview of Yoga research for health and well-being. Journal of Yoga \& Physical Therapy 5: 4.

6. Patwardhan AR (2017) Yoga research and public health: Is research aligned with the stakeholders' needs? Journal of Primary Care \& Community Health 8(1): 31-36.

7. Ross A, Bevans M, Friedmann E, Williams L, Thomas Sue (2014) “I am a nice person when I do yoga". Journal of Holistic Nursing 32(2): 67-77.

8. Shroff FM, Asgarpour M (2017) Yoga and mental health. Journal of Physiotherapy \& Physical Rehabilitation 2: 1 .

9. López-Otín, Blasco MA, Partridge L, Serrano M, Kroemer G (2013) The Hallmarks of Aging. Cell 153(6): 1194-1217. 
(C) Co $\begin{aligned} & \text { This work is licensed under Creative } \\ & \text { Commons Attribution 4.0 License } \\ & \text { DOI: } 10.19080 / J Y P .2018 .06 .555684\end{aligned}$

\section{Your next submission with Juniper Publishers} will reach you the below assets

- Quality Editorial service

- Swift Peer Review

- Reprints availability

- E-prints Service

- Manuscript Podcast for convenient understanding

- Global attainment for your research

- Manuscript accessibility in different formats

( Pdf, E-pub, Full Text, Audio)

- Unceasing customer service

Track the below URL for one-step submission

https://juniperpublishers.com/online-submission.php 